\title{
Approval Document
}

National Cancer Institute

\section{Source}

National Cancer Institute. Approval Document. NCI Thesaurus. Code C70799.

A document containing a formal acceptance as satisfactory, and/or official agreement or permission. 